Review Article

\title{
Noise pollution and post-COVID-19 pandemic mobility: a case for ambient noise
}

\author{
Mohan Kumar, Gitismita Naik*
}

Department of Community and Family Medicine, All India Institute of Medical Sciences, Raipur, Chhattisgarh, India

Received: 26 November 2021

Revised: 20 January 2022

Accepted: 24 January 2022

\section{*Correspondence:}

Dr. Gitismita Naik,

E-mail: gitismita@gmail.com

Copyright: ( ) the author(s), publisher and licensee Medip Academy. This is an open-access article distributed under the terms of the Creative Commons Attribution Non-Commercial License, which permits unrestricted non-commercial use, distribution, and reproduction in any medium, provided the original work is properly cited.

\begin{abstract}
Noise as a hindrance to health is a low priority in India. The existing statutory controls for noise pollution in India are highly inadequate amidst an implementation gap and should better suit Indian culture and social set-up. Though ubiquitous in nature, community noise and industrial noise are the two major settings from where noise occurs. Exposure to noise above the threshold and over prolonged periods can lead to auditory and non-auditory effects on health; including but not limited to cardiovascular diseases, neurosis, mental illness, stomach ulcers, respiratory disorder exacerbations, sleep disturbances, fetal and maternal complications, child developmental disabilities, psychological dysfunctions/ negative social behavior, road traffic and industrial accidents. The social and economic costs associated with noise pollution are manifold. COVID-19 pandemic has forced countries worldwide to enforce lockdowns resulting in an involuntary ambient noise reduction and other ecological changes like cleaner rivers and air. To sustain the environmental 'gains' of enforced lockdowns, it is important for national governments and international health agencies to emphasize better implementation of rules governing pollution in addition to adopting/adapting newer proven technologies; making post-COVID-19 pandemic mobility more environmentally sound, healthy and sustainable. Noise pollution mitigation strategies should be worked out at city levels and having a coordinated and long-term integrated noise pollution research is the need of the hour.
\end{abstract}

Keywords: Noise pollution, COVID-19, Health effects, Noise mitigation, Ambient noise

\section{INTRODUCTION}

"Quiet places have been on the road to extinction at a rate that far exceeds the extinction of species". Environmental noise has become a symbol of pervasive inequality. 1 It is an important public health issue, featuring among the top environmental risks to health with broadening extent and severity as a result of industrialization, urbanization and technological advancement. ${ }^{2}$ It is a growing concern among both the general public and policy-makers owing to the negative impacts on human health and well-being. In early 1859 Florence Nightingale recognized noise as a health hazard when she wrote "Unnecessary noise is the cruellest abuse of care which can be inflicted on either the sick or the well". ${ }^{3}$ The word noise is derived from Latin word "Nausea" implying "unwanted sound" or sound that is loud, unpleasant or unexpected. It can be defined as wrong sound, in the wrong place and at the wrong time. $^{4}$

Noise pollution is defined as regular exposure to elevated sound levels that may lead to adverse effects in humans or other living organisms. According to the world health organization (WHO) and U.S. Environmental Protection Agency (EPA), sound levels $<70 \mathrm{~dB}$ are not damaging to living organisms, regardless of how long or consistent the exposure is; though the no observed effect level (NOEL) for night noise is as low as $30 \mathrm{~dB} .{ }^{5}$ Exposure for more than 8 hours to constant noise beyond $85 \mathrm{~dB}$ may be 
hazardous; $85 \mathrm{~dB}$ is roughly equivalent to the noise of heavy truck traffic on a busy road. ${ }^{6}$

According to WHO estimates, $10 \%$ of the global population is currently exposed to noise levels that could lead to hearing impairment and 1.1 billion young people (aged between 12-35 years) are at risk of hearing loss due to exposure to noise in recreational settings. ${ }^{7}$ Road traffic noise is said to contribute to at least 12,000 premature deaths annually in Europe, amounting to a loss of 1.6 million high-quality-life days. ${ }^{8}$ The current estimates of $83 \%$ gap in hearing aid need and use, i.e., only $17 \%$ of those who could benefit from use of a hearing aid actually use one. ${ }^{9}$

\section{SCENARIO IN INDIA}

In India, noise was regarded as a pollutant under the air (Prevention and control of pollution) Act, $1981 .^{10}$ The data on nationwide estimates of people exposed to hazardous levels of noise and burden of noise induced hearing loss (NIHL) at the community level is scarce and available studies are disproportionately in the national capital. ${ }^{11}$ Noise as a hindrance to health is a low priority in India with lots of other pressing issues, and a societal acceptance of noise. In India, residential areas, schools, hospitals can be besides heavy traffic roads, or railway tracks. Cultural or religious functions are also loud and noisy and seldom follow regulations to limit noise. The luxury of silence is more evident in India with gated neighborhoods and dense urban slums at the extremes of the noise spectrum. Besides till now there is no citizen activism with relation to noise in India (as against western societies) with a general attitude of accepting noise as a byproduct of urban life. ${ }^{12}$

It has been shown in surveys from central pollution control board (CPCB) and national environmental engineering research institute (NEERI) that the noise levels in residential, commercial and industrial areas and silent zones of Delhi and towns of national capital region (NCR) far exceed the prescribed standards with an average noise level of $80 \mathrm{~dB}$ while the ambient limit is 55 $\mathrm{dB} .{ }^{13}$ Shetye et al had estimated that noise level in crowded locations in Bombay was almost double that of residential standards adopted by most countries. During the festival of Diwali, the average ambient noise level ranged from 76 to $80 \mathrm{~dB}(\mathrm{~A})$, which was 1.2-1.3 times higher than on normal days (57-69 dB[A] Leq). Such intense high impact noise emitted by fireworks pose a great risk, and can result in damage to the auditory apparatus. $^{14}$

The statutory control of noise pollution in India is dealt by the article 21 of constitution of India, criminal procedure code and noise control (Under the Sec. 133 of the criminal procedure code, 1973), the noise pollution (Control and regulation) rules, 2000 (Under environment protection act 1996) and the motor vehicle Act. ${ }^{15-18}$ But these enactments are highly inadequate amidst an implementation gap and should better suit Indian culture and social set-up. Also, there should be promulgation of noise standards from varied part sources at specific time of the day by the government.

\section{EXISTING STANDARDS}

The ambient air quality standards in respect of noise is given by noise pollution (Control and regulation) rules, 2000 for four different areas namely industrial, commercial, residential areas and silence zones as summarized in Table $1 .{ }^{17}$

\section{Table 1: Ambient air quality standards in respect of noise.}

\begin{tabular}{|llll|}
\hline $\begin{array}{l}\text { Area } \\
\text { code }\end{array}$ & $\begin{array}{l}\text { Category of } \\
\text { area/zone }\end{array}$ & \multicolumn{2}{l|}{ Limits of dB(A) Leq } \\
\hline (A) & Industrial area & 75 & 70 \\
\hline (B) & Commercial area & 65 & 55 \\
\hline (C) & Residential area & 55 & 45 \\
\hline (D) & Silence zone & 50 & 40 \\
\hline
\end{tabular}

Day time shall mean from 6.00 a.m. to 10.00 p.m., Night time shall mean from 10.00 p.m. to 6.00 a.m., silence zone is defined as an area comprising not less than 100 metres around hospitals, educational institutions and courts. The silence zones are zones which are declared as such by the competent authority and mixed categories of areas may be declared as one of the four mentioned categories by the competent authority.

The WHO guidelines for community noise recommend $<30 \mathrm{~dB}[\mathrm{~A}]$ in bedrooms during the night for a sleep of good quality and $<35 \mathrm{~dB}[\mathrm{~A}]$ in classrooms to allow good teaching and learning conditions. The WHO guidelines for night noise recommend $\angle 40 \mathrm{~dB}[\mathrm{~A}]$ of annual average (L night) outside of bedrooms to prevent adverse health effects from night noise. ${ }^{19}$

\section{SOURCES OF NOISE POLLUTION}

There are two major settings where noise occurs, viz., community noise and industrial noise. Community noise (also called environmental noise, residential noise, or domestic noise) is defined as noise emitted from all sources, except noise at the industrial workplace. ${ }^{20}$

Noise is ubiquitous; developed or developing country, rural or urban. It is so omnipresent in today's society that we often fail to even notice it anymore. The major sources are: ${ }^{21}$ Traffic sounds from cars, buses, pedestrians, ambulances etc. especially vehicular horns, Construction sites, from drilling or other heavy machinery in operation, Industrial sites, from fans, generator sets, compressor, mills, Train stations, especially people near rail roads, Airports, from air traffic, i.e. planes taking off or landing, Workplace sounds, especially open-space offices, Household noise, from loud music, television, use of grinding machineries, vacuum cleaners, fans and coolers, washing machines, dishwashers, lawnmowers etc. Market/commercial areas, 
Recreational exposure to loud sounds such as that from use of personal audio devices at high volumes and for prolonged periods of time and regular attendance at concerts, nightclubs, bars and sporting events, Events involving fireworks, firecrackers, loudspeakers etc. and at times of conflicts, noise pollution through explosions, gunfire etc.

\section{HUMAN DISEASES CAUSED BY NOISE POLLUTION}

Exposure to noise above the threshold and over prolonged periods can lead to auditory and non-auditory effects on health. Hearing loss and tinnitus are direct effects of noise pollution. It is also a nonspecific stressor that has been shown to have an adverse effect on human health and wellbeing, especially following long-term exposure. The psychological and physiological distress due to noise causes disturbance of the organism's homeostasis and increasing allostatic load. ${ }^{22,23}$ The effects of noise pollution on human health are:

Cardio vascular dysfunction, especially hypertension, coronary heart disease, myocardial infarction, heart failure and stroke due to activation of the autonomic and endocrine systems by stress reactions caused by traffic noise. It has been estimated that exposure to noise pollution above levels recommended by WHO lead to additional 542 cases of heart attack, 788 cases of stroke and 1169 cases of dementia in the UK in a year. ${ }^{22,24}$

Sudden and excessive noise (e.g., explosives) can become physically painful giving rise to neurosis, mental illness, stomach ulcers and respiratory disorder exacerbations. ${ }^{25}$

When noise levels reach dangerous levels, such as around $140 \mathrm{~dB}$ for adult or $120 \mathrm{~dB}$ for children or when the exposure is continuous and over $85 \mathrm{~dB}$ hearing loss occurs. People of all ages, including children can develop noise induced hearing loss (NIHL). ${ }^{26}$

Noise annoyance (Aversion/distress): An emotional and/or attitudinal reaction from a person exposed to noise in a given context. ${ }^{27}$

Other auditory problems like abnormal loudness perception (loudness recruitment), distortion (paracusis), and tinnitus. ${ }^{23}$

Sleep disturbances, a serious condition in that they can affect everyday performance and lead to serious diseases (noise hinders the therapeutic ability of sleep). ${ }^{28,29}$

Women exposed prenatally to high noise levels $(\geq 80 \mathrm{~dB})$ are at a significantly higher risk for having small-forgestational-age newborn, gestational hypertension and infant with congenital malformations. Though the risk of preeclampsia, perinatal death, spontaneous abortion and preterm birth were raised with increasing levels of noise pollution this was not statistically significant. ${ }^{30,31}$
Child development: Children are more sensitive to noise pollution, and a number of noise-pollution-related diseases and dysfunctions are known to affect children, from hearing impairment to psychological, learning/comprehension and physical effects. ${ }^{32}$

Dementia, favored or compounded by noise pollution. ${ }^{33}$

Psychological dysfunctions/negative social behavior: These reactions include anger, disappointment, dissatisfaction, aggressiveness, unfriendliness, nonparticipation or disengagement, withdrawal, helplessness, depression, anxiety, distraction, agitation, or exhaustion. Lack of perceived control over the noise intensifies these effects. It has also been shown that noise sensitivity was significantly associated with internalizing, externalizing, and total behavioral problems. ${ }^{34}$

Speech interference and effect on communication may affect efficiency of offices, schools and other places where communication is of vital importance. ${ }^{35}$

Increased residential mobility, healthcare utilization/hospital admissions and drug consumption. ${ }^{23}$

Road traffic and industrial accident rates: The possible mechanisms include lack of attention, masking of important auditory signals such as warning auditory communications, sirens and machinery sounds indicating impending danger due to NIHL or use of personal hearing protection to counter noise. ${ }^{36}$

Social and economic costs of noise pollution: Sleep disturbance because of noise pollution affects the individual's work performance and productivity during the day, in addition to cardiovascular diseases and related health costs. In a study to estimate the cost of these health impacts using quality adjusted life years (QALYs) and by valuing a year of healthy life at $£ 60000$ (€74002), it was found that these health impacts together had a cost of $£ 1.09$ billion ( $€ 1.34$ billion)..$^{22,37}$

Noise as a social inequity divider: How the poor do not have the resources to reduce ambient noise pollution, but the rich can spend on it. It also applies to how economic status influences the residential locality and noise in surrounding areas. ${ }^{38}$

Effect on birds and other animals: Birds reportedly do not migrate to places with excess noise. Also, noise pollution can lead to miscarriage in other mammals or birds don't lay eggs in noisy environment. ${ }^{39}$

Effects of noise pollution on marine life: Whales are among the most affected, as their hearing helps them orient themselves, feed and communicate. Noise pollution thus interferes with cetaceans' (whales and dolphins) feeding habits, reproductive patterns and migration routes, and can even cause hemorrhage and death. ${ }^{40}$ 


\section{COVID-19 PANDEMIC ENFORCED LOCKDOWN AND ITS EFFECTS ON NOISE POLLUTION}

COVID-19 pandemic has forced countries worldwide to enforce lockdowns to contain the transmission of SARSCoV-2. India went into complete national lockdown on $24^{\text {th }}$ March 2020. The lockdown led to an involuntary ambient noise reduction, also leading to other ecological changes like cleaner rivers and air. ${ }^{41}$

National geographic to describe the phenomenon of a hushed planet as an unintended consequence of national lockdowns the world over has coined the term 'global quieting'. ${ }^{42}$ The scientists at university of London have reported a 30\% drop in seismic noise near King's cross station, while Dr. David Cornwell, a geophysicist at the University of Aberdeen, has recorded a drop in campus noise levels of $65 \%$ since the students were sent home mid-March. ${ }^{43}$ According to Sindh environmental protection agency (SEPA) the noise pollution had decreased by $40 \%$ in the port city Karachi. ${ }^{44}$ In a study conducted in Eastern India using image and field data in pre and during lockdown periods, to assess the impact of forced lockdown on environmental components, it was found that noise level dropped to $<65 \mathrm{~dB}[\mathrm{~A}]$ which was above $85 \mathrm{~dB}[\mathrm{~A}]$ in pre lockdown period. ${ }^{45}$

\section{SUSTAINING THE GAINS ACHIEVED IN TERMS OF NOISE POLLUTION}

Governments of most developed countries especially those in pan-European region had launched UN Task Force to make post-COVID-19 pandemic mobility more environmentally sound, healthy, and sustainable. This was with the vision to sustain the gains of enforced lockdowns. For instance, the transport sector now has the possibility and the obligation to restart in a manner that is conducive to a more efficient, greener, healthier, and more sustainable system. To do so, a "new normal" needs to be developed.

Its importance is felt. As union environment minister Prakash Javadekar said, "To sustain the environmental 'gains' of the coronavirus lockdown during normal times, it is important that states and the union territories should strictly implement relevant rules governing pollution."

\section{CONCLUSION}

Noise pollution limits are being breached in almost all Indian cities and particularly worse in urban areas. Further exploratory studies comprising assessment of socio-demographic factors, noise descriptors, noise mapping, prediction by noise modeling, co-morbidities, population specific thresholds for normal or impaired hearing and experimental studies to demonstrate exposure-effect relationship, advanced study on acoustic absorption material are urgently required, in addition to ways on consolidating the gains of enforced lockdown on reducing average environmental noise levels. City-wise noise pollution mitigation strategies should be worked out at all levels. A coordinated and long-term integrated noise pollution research is the need of the hour.

\section{Recommendations}

Fortunately, hearing loss due to community noise pollution is largely preventable. We recommend some best practices that were tested and successfully implemented to control noise pollution across countries.(46-48) They are: Awareness campaigns ensuring community participation. Basic and essential information such as noise levels created by common sources of noise pollution, adverse health effects on both the person creating noise, and the public preventive measures and conditions punishable under law should be extensively disseminated. School campaigns, health education programs, and publicizing through print and electronic media, graphic displays in public places. Involvement of non-governmental organizations in generating public interest and co-operation in addition to providing audiological facilities will immensely help the cause. Developing and enforcing of relevant legislation. To ban industrial and noisy trades or works in residential areas and if possible, choosing residential areas as far removed from industries and heavy traffic. Use personal protective equipment such as earmuffs and earplugs in industrial settings should be encouraged. Use of noiseabsorbent materials should be made mandatory. Ban on pressure horns, phasing out of three-wheeler autos. Proper planning of roadways. Green streets act as noise reducing devices with an insertion loss between 5 and $15 \mathrm{~dB}(\mathrm{~A})$ depending on the frequency (Noise attenuation). Use of trees, grass, ground, hedges, green barriers interposed in the path of sound propagation, absorb part of it by diminishing the sound coming to a receiver or to the facades. This is in addition to the visual attractiveness as well as the improvement in the sound perception in presence of vegetation. Compensation to affected individuals or people. Flying of air crafts, below a definite altitude, near the cities should not be allowed except under emergency conditions. Fireworks especially those of exploding nature should be discouraged. Environment courts should be established for control of noise. Efficient engineering products. Encouraging individuals to use personal protective devices such as earplugs and noise-cancelling earphones and headphones; promoting safe listening to reduce the risk of recreational NIHL through the WHO make listening safe initiative and avoid prolonged use of earphones, especially at elevated sound levels

Funding: No funding sources Conflict of interest: None declared Ethical approval: Not required

\section{REFERENCES}

1. Dreger S, Schüle S, Hilz L, Bolte G. Social Inequalities in Environmental Noise Exposure: A 
Review of Evidence in the WHO European Region. Int J Environ Res Public Health. 2019;16(6):1011.

2. McMichael AJ. The urban environment and health in a world of increasing globalization: issues for developing countries. Bull World Health Organ. 2000;78(9):1117-26.

3. Al-Tarawneh OM, D'emeh WM, Yacoub MI. An assessment of nurses' knowledge regarding noise in intensive care units in Jordan. Int J Afr Nurs Sci. 2020;12:100183.

4. Younes I, Shafiq M, Ghaffar A, Mehmood S. Spatial Patterns of Noise Pollution and Its Effects in Lahore City. Anchor Academic Publishing; 2017;117.

5. Noise Control Act. US EPA, 2013. Available from: https://www.epa.gov/laws-regulations/summarynoise-control-act. Accessed on Oct 13, 2020.

6. Chepesiuk R. Decibel Hell: The Effects of Living in a Noisy World. Environ Health Perspect. 2005;113(1).

7. WHO. 1.1 billion people at risk of hearing loss. Available at: https://www.who.int/mediacentre/news/releases/2015 /ear-care/en/. Accessed on Oct 13, 2020.

8. Noise - European Environment Agency. Available at: https://www.eea.europa.eu/themes/human/noise. Accessed on Oct 13, 2020.

9. Deafness and hearing loss. Available at: https://www.who.int/news-room/fact-

sheets/detail/deafness-and-hearing-loss. Accessed on Oct 13, 2020.

10. The air (prevention and control of pollution) act, 1981. Available at: http://legislative.gov.in/sites/default/files/A198114.pdf. Accessed on Oct 13, 2020.

11. Nongkynrih B, Gupta S, Jamir L. Community noise pollution in urban India: Need for public health action. Indian J Community Med. 2014;39(1):8.

12. Berti Suman A, van Geenhuizen M. Not just noise monitoring: rethinking citizen sensing for risk-related problem-solving. J Environ Plan Manag. 2020;63(3):546-67.

13. Temporal and Spatial Fluctuation of Noise Levels in the Closed Vicinity of Urban Roadways. Int J Recent Technol Eng. 2019;8(3):5983-9.

14. Shetye RP, Kapoor RK, Mahadevan TN. The noise festivals: can we not change? Scavanger. 1981;3- 8.

15. Article 21 of The Constitution of India. Available at: http://www.legalserviceindia.com/articles/art222.htm 1. Accessed on Oct 13, 2020.

16. The code of criminal procedure. 1973. Available at: https://www.oecd.org/site/adboecdanticorruptioninitiative/46814340.pdf. Accessed on Oct $13,2020$.

17. The Noise Pollution (Regulation and Control) Rules. 2000. Ministry of environment and forests. Available from: http://dstegoa.gov.in/Noise\%20rules-10-082017.pdf. Accessed on Oct 13, 2020.

18. The motor vehicles act, 1988. Available at: http://legislative.gov.in/sites/default/files/A198859.pdf Accessed on Oct 13, 2020.
19. Hurtley C, World Health Organization, editors. Night noise guidelines for Europe. Copenhagen, Denmark: World Health Organization Europe. 2009;162.

20. Guidelines for Community Noise-Executive summary. Available at: https://www.who.int/docstore/peh/noise/ComnoiseEx ec.htm. Accessed on Oct 13, 2020.

21. Noise sources. WHO. Available at: https://www.who.int/occupational_health/publication s/noise5.pdf. Accessed on Oct 13, 2020.

22. Theakston F. Burden of disease from environmental noise: quantification of healthy life years lost in Europe. Copenhagen: World Health Organization, Regional Office for Europe. 2011;106.

23. Basner M, Babisch W, Davis A, Brink M, Clark C, Janssen S, et al. Auditory and non-auditory effects of noise on health. The Lancet. 2014;383(9925):132532.

24. Münzel T, Sørensen M, Schmidt F, Schmidt E, Steven S, Kröller-Schön S et al. The Adverse Effects of Environmental Noise Exposure on Oxidative Stress and Cardiovascular Risk. Antioxid Redox Signal. 2018;20;28(9):873-908.

25. Evans GW, Bullinger M, Hygge S. Chronic noise exposure and physiological response: A prospective study of children living under environmental stress. Psychological science. 1998;9(1):75-7.

26. Hearing loss due to recreational exposure to loud sounds, A review. WHO. Available at: https://www.who.int/pbd/deafness/Hearing_loss_due _to_recreational_exposure_to_loud_sounds.pdf. Accessed on Oct 13, 2020.

27. Beutel ME, Jünger C, Klein EM, Wild P, Lackner K, Blettner $\mathrm{M}$ et al. Noise Annoyance Is Associated with Depression and Anxiety in the General Population-The Contribution of Aircraft Noise. Andrade-Navarro MA, editor. PLOS ONE. 2016;11(5):e0155357.

28. Raja RV, Rajasekaran V, Sriraman G. Non-auditory Effects of Noise Pollution on Health: A Perspective. Indian J Otolaryngol Head Neck Surg. 2019;71(S2):1500-1.

29. Halperin D. Environmental noise and sleep disturbances: A threat to health? Sleep Sci. 2014;7(4):209-12.

30. Nieuwenhuijsen M, Ristovska G, Dadvand P. WHO Environmental Noise Guidelines for the European Region: A Systematic Review on Environmental Noise and Adverse Birth Outcomes. Int J Environ Res Public Health. 2017;14(10): 1252.

31. Ristovska G, Laszlo H, Hansell A. Reproductive Outcomes Associated with Noise Exposure-A Systematic Review of the Literature. Int J Environ Res Public Health. 2014;11(8):7931-52.

32. Stansfeld S, Hygge S, Clark C, Alfred T. Night time aircraft noise exposure and children's cognitive performance. Noise Health. 2010;12(49):255.

33. Paul KC, Haan M, Mayeda ER, Ritz BR. Ambient Air Pollution, Noise, and Late-Life Cognitive 
Decline and Dementia Risk. Annu Rev Public Health. 2019;40(1):203-20.

34. Schubert M, Hegewald J, Freiberg A, Starke K, Augustin F, Riedel-Heller S, et al. Behavioral and Emotional Disorders and Transportation Noise among Children and Adolescents: A Systematic Review and Meta-Analysis. Int J Environ Res Public Health. 2019;16(18):3336.

35. Zaheeruddin, Jain VK. An expert system for predicting the effects of speech interference due to noise pollution on humans using fuzzy approach. Expert Syst Appl. 2008;35(4):1978-88.

36. Noise and accidents-a review. Ann Occup Hyg. 1982 Aug $1 ; \quad$ Available at: https://academic.oup.com/annweh/article/25/3/249/2 61579/NOISE-AND-ACCIDENTSA-REVIEW. Accessed on Oct 13, 2020.

37. Dzhambov AM, Dimitrova DD. Evaluation of the social and economic burden of road traffic noiseattributed myocardial infarction in Bulgarian urban population/Procjena socijalnog i ekonomskog tereta infarkta miokarda povezanog $\mathrm{s}$ cestovnom bukom $\mathrm{u}$ bugarskog urbanog stanovništva. Arch Ind Hyg Toxicol. 2015;66(1):15-21.

38. Seltenrich N. Inequality of Noise Exposures: A Portrait of the United States. Environ Health Perspect. 2017;125(9):094003.

39. Effects of noise pollution on birds: A brief review of our knowledge. Ornithol Monogr. 2012;74(1):6-22.

40. Weilgart LS. The Impact of Ocean Noise Pollution on Marine Biodiversity. Available at: https://awionline.org/sites/default/files/uploads/docu ments/Weilgart_Biodiversity_2008-123810585110133.pdf. Accessed on Oct 13, 2020.

41. Arora S, Bhaukhandi KD, Mishra PK. Coronavirus lockdown helped the environment to bounce back. Sci Total Environ. 2020;742:140573.

42. These photos reveal a hushed world. National Geographic. 2020. Available at: https://www.nationalgeographic.co.uk/photography/2 020/05/these-photos-reveal-hushed-world. Accessed on Oct 13, 2020.

43. UK seismic noise "down by 20 to 50 percent" during lockdown. BBC Science Focus Magazine. Available at: https://www.sciencefocus.com/news/uk-seismicnoise-down-by-20-to-50-per-cent-during-lockdown/. Accessed on Oct 13, 2020.

44. SEPA data shows up to $40 \%$ reduction in air, noise pollution in Karachi. The Express Tribune. 2020. Available at: http://tribune.com.pk/story/2236166/sepa-datashows-40-reduction-air-noise-pollution-karachi. Accessed on Oct 13, 2020.

45. Mandal I, Pal S. COVID-19 pandemic persuaded lockdown effects on environment over stone quarrying and crushing areas. Sci Total Environ. 2020;732:139281.

46. Yuen F. A vision of the environmental and occupational noise pollution in Malaysia. Noise Health. 2014;16(73):427.

47. Reduce the Noise. Ocean care. Available at: https://www.oceancare.org/wpcontent/uploads/2019/01/Report_Reduce-theNoise_190124.pdf. Accessed on Oct 13, 2020.

48. Reducing noise pollution-success stories-European Environment Agency. Available at: https://www.eea.europa.eu/highlights/reducingnoise-pollution-success-stories. Accessed on Oct 13, 2020.

Cite this article as: Kumar M, Naik G. Noise pollution and post-COVID-19 pandemic mobility: a case for ambient noise. Int J Community Med Public Health 2022;9:1097-102. 